\title{
Balanced production planning and control in production networks
}

\author{
Hans-Peter Wiendahl and Michael Höbig \\ University of Hanover \\ Callinstrasse 36, 30167 Hannover, Germany \\ Telephone: $\quad++49 / 511 / 762-3256$ \\ Fax: $\quad++49 / 511 / 762-3814$
}

\begin{abstract}
Companies are beginning to establish cooperative projects that are growing into production networks in order to realize synergetic potentials by concentrating on core competencies. These networks involve some basic structural demands. This paper describes these demands as well as the role of a logistics network coordinator.
\end{abstract}

\section{Keywords}

Production network, cooperation, logistics network coordinator

\section{INTRODUCTION}

The organization of production processes will have to adopt new concepts in order to meet the challenge of increasing global competition, shorter production cycles and mass customization. Simultaneously with the re-engineering of internal processes, the concentration on core competencies and short lead times is compelling more and more companies to join forces in production networks. In the following paper, we describe the idea of production networks as well as some instruments for the balanced planning and control of such networks. 


\section{BASICS OF PRODUCTION NETWORKS}

A general trend towards increased cooperation is emerging with stepped optimization and concentration on the basis of core components in the subsequent phases. In the past cooperation in the areas of research and development has already proved its worth; and today, links between buying, production and supply are becoming increasingly common. The outcome of this, via customer-supplier links (logistic chains), is the formation of stable network arrangements and also, in a further development stage, the variable production network.

Production networks can come into existence for different and companyspecific reasons. According to existing knowledge, there are four basic network types, each with specific characteristics (Buse et al 1997). These types are

- Strategic Networks,

- Regional Networks,

- Virtual Enterprises and

- Operational Networks.

For all these types, there is a need for cooperative order processing, the requirements for which are shown below.

\section{REQUIREMENTS FOR COOPERATIVE ORDER PROCESSING}

\subsection{Stages of transparency}

An essential requirement for network-wide order-processing is the transparency of required data. The more data exchange there is, the more detailed the information of the network partners is, in terms of synchronized PPC. Depending on the intensity of the connection and the trust between the partners, the possibilities of process design increase with the level of data exchange (Figure 1).
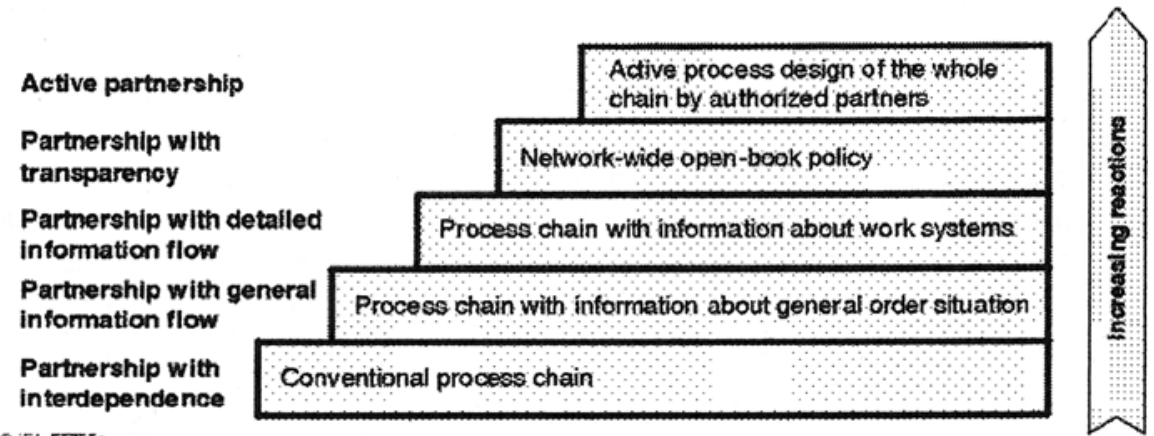

DiFA. Farsse

Figure 1 Stages of logistic transparency of network-partners 
Beginning with the conventional process chain there exist only classic customer-supplier relationships. The flow of information is limited to the order part number, delivery date and quantity, for example - and the delivery. Thus there is little possibility for the logistical tuning of the processes on either side.

The next step to enhance the volume of data flow is the provision of general loading information by the partners in a network. This enables the lead time and the deviation from the plan to be estimated in order to assess the actual reliability of order fulfillment by the partner.

To ensure this, it is necessary to give more detailed information about the orders. Because the orders depend on the resources of production, the main work systems have to be monitored. If such data is exchanged, the partners can judge the order status of their own production because they know how secure the supply of the partners will be. It is also possible to shift some orders to the supplier in the event of a system overload.

One step beyond this is the network-wide open-book policy. In this set-up, every partner can see the whole network with all orders and resources. The order processing is therefore very transparent and a balance of the network becomes easier to achieve. This transparency demands a lot of trust between the partners and a common business basis.

The highest stage of transparency is the transition from a passive partnership to an active one. The order fulfillment can be influenced by every partner who is authorized to do this. With the availability of information, active process design is possible. This promises a further step in the adjustment of production planning and control. It even enables the partners to realize certain potentials in the network which do not lie within their sole capability. Thus even partners who are not in a dominant position in a network have the opportunity to take over the manufacture of an order which would otherwise not meet the planned due date.

\subsection{Rules for cooperation}

The cooperative work in a network has to be based on a common view concerning the manufacture of products. This mutuality will become apparent in the development of rules for cooperation. These rules can vary in detail and may differ according to the network objectives, but fundamentally there are a handful of existential ones, as exemplified in figure 2.

The customer's demands are the basis for all order fulfillment. All effort is primarily geared to the satisfaction of those wishes. All of the information given to the partners should be used only for the efficient manufacture of the products. Above all it is necessary to respect the other partners' know-how. Furthermore the benefit of the performance increase achieved by the partners has to be shared between those who initiated it, but it should also bring advantage to the whole network. This can take the form of a financial benefit, for example, or a boost in the performance or image of the network. 
- The common understanding of the fulfillment of the customer's demands is the basis for cooperative order processing.

- All information published between partners should only serve the fulfillment of the objectives of manufacturing.

- The knowledge of problems in order-processing places no responsibility on other network partners. Conversely there is a responsibility to draw attention towards such problems.

- The optimization of the complete network has priority over the optimization of single processes.

- All partners agree to follow the instructions of the coordinator.

- The continuous improvement of processes - even at partners' own costs - is an essential prerequisite for an alliance of the best.

- The results of improvements in efficiency shall provide incentives for further developments and at the same time be of advantage to the customer.

\section{Figure 2 Rules for cooperation in a production network}

For the operation of a network it is indispensable that the partners are coordinated in respect of the requirements that have just been discussed. This coordination task can be described as follows.

\section{LOGISTICS NETWORK COORDINATOR - A NEW ROLE FOR THE BALANCE OF NETWORKS}

The cooperation of enterprises in a network creates special demands in respect of operational tasks. In order to react to these demands it is necessary to have a central function in such a network, where the information for the control of the network is handled. This function can be carried out by a logistics network coordinator. The tasks of such a function and some instruments for achieving balance are described below.

\subsection{Tasks of a Logistics Network Coordinator}

The tasks of a network coordinator depend on the type of network in which he is involved. The importance of such a role is less in a regional network than in a virtual enterprise and an operational network, and it is greatest in a strategic network (Figure 3).

In each network it is the coordinators task to determine the order allocation because of his knowledge of the logistic situation of the partners. Some other logistic tasks, such as the controlling of orders and resources, gain significance with the intensity of cooperation between the partners. In a strategic network the spectrum of tasks comprises even structural functions like the logistic analysis of products and process chains. 


\begin{tabular}{|c|c|c|c|c|c|}
\hline & \multicolumn{4}{|c|}{ Types of networks } \\
\hline & & $\begin{array}{l}\text { Regionat } \\
\text { Nework }\end{array}$ & $\begin{array}{c}\text { Virtual } \\
\text { Enterprige }\end{array}$ & $\begin{array}{l}\text { Opetational } \\
\text { Network }\end{array}$ & $\begin{array}{l}\text { Strategic } \\
\text { Network }\end{array}$ \\
\hline \multirow{6}{*}{$\frac{\frac{n}{6}}{5}$} & $\begin{array}{l}\text { Network-wide } \\
\text { material planning }\end{array}$ & & & & \\
\hline & $\begin{array}{l}\text { Capacily criented } \\
\text { preliminary scheduling } \\
\text { in form of ba sic due dates }\end{array}$ & & & & \\
\hline & Oroter allocation & & & & \\
\hline & 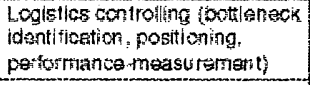 & & & & \\
\hline & $\begin{array}{l}\text { Froduct stucture analysis } \\
\text { and design ol logistic chatis }\end{array}$ & & & & \\
\hline & $\begin{array}{l}\text { Prescription of general } \\
\text { condilions (contracts. } \\
\text { strategic orentation) }\end{array}$ & & & & \\
\hline
\end{tabular}

Figure 3 Tasks of a coordinator in different network types

Supporting instruments for these tasks can be divided into logistics design and operation. Some of these instruments have the same importance in internal use, others are more important in networks.

\subsection{Instruments for logistics design}

The logistics design gains importance dependent on the customer's request for quick response. In order to improve the logistic performance of a network, the structure of the processes has to be plotted and potentials have to be pointed out. Accordingly, a product structure model which includes an order diagram has been developed (Wahlers/Mittendorf 1997). The product structure is build up hierarchically in an assembly-oriented way.

An order structure can be derived from a product structure, showing all processes to be carried out for the fulfillment of a customer's order. In this, all procurement, manufacturing and assembly processes and their interdependencies are plotted as in a Gantt diagram. This means the linkage of all parts of the order net with a visualization of their order content and their lead time. The work content of all orders is accumulated over the scheduled due dates. This allows the identification in the order net of large workloads and operations likely to cause longer lead times.

As with the scheduled due dates, the actual status with realized dates can be shown. A comparison of these dates shows the deviation of single operations and - due to the interdependencies in the product structure - of the whole order net.

In the first step only the mean deviation of the operations is shown. However, the deviation consists not only of the average of all operations but also of the variation. For example, the constant deviation of a single order can be taken into 
consideration in the planning phase of such an order net. Varying deviations, conversely, cannot be scheduled, so that due dates become unreliable. The more complex an order net, the more uncertain the dependent operations become.

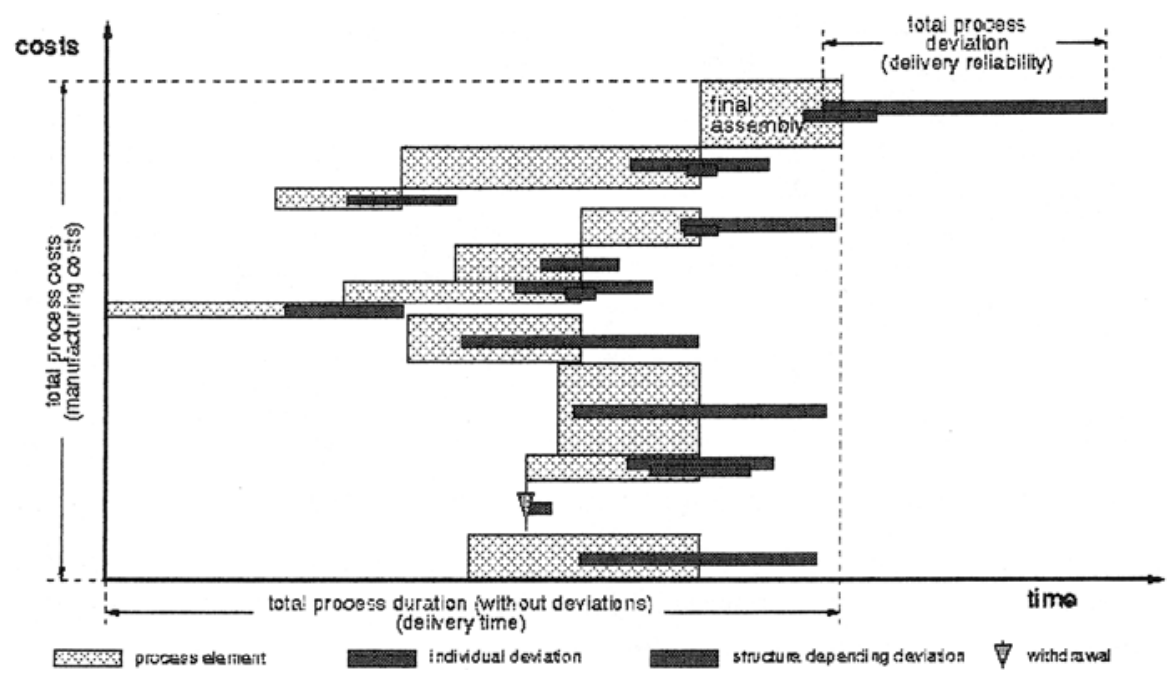

Figure 4 Logistical product model

For the monitoring of the logistic potentials of an order net, the logistical product model (Fig. 4) was developed (Wahlers/Mittendorf 1997). It replaces the work content in the order diagram by the process costs. In addition to the process duration, the variation of the observed process and that of the whole path to which the process belongs are displayed. By this depiction the analysis of the order net concerning the delivery time and delivery reliability can be shown in relation to the costs. The combination of these instruments allows the coordinator to measure the potential of the network and to judge alternatives in supply or order allocation in a production network.

\subsection{Instruments for coordinated planning and control}

The coordination of planning and control in production networks consists of various tasks as shown above. Approaches are depicted below for some of these tasks, namely order allocation, subcontracting and potential analysis.

\subsubsection{Order allocation}

The conflicting competitive objectives of the market and the enterprises call for a balancing of these objectives to achieve satisfactory efficiency. Production networks offer even more possibilities for such a balance. The situation often arises that there are redundancies of resources. These redundancies offer a chance to 
compensate the different loading of identical or similar work systems. By this compensation the utilization can be increased and it is possible to obtain shorter queues in front of the work systems.

The relation between inventory, performance and range shows that the shortening of queues produces shorter lead times. By this means, the network can be balanced. The following paragraphs present an approach to the procedure for customer order allocation. The allocation process starts with a customer's order. The first criterion is the possibility of part deliveries. If this is possible, the order can be divided into parts of identical delivery date and/or the same stocking and production location, and the process can be continued.

In networks which have several assembly locations for the supplied material, the stock-on-hand of the finished products at the stocking locations has to be compared to the demand. If the stock-on-hand of all parts of the customer order is sufficient, the allocation process goes on to the question of whether the products are available near the customer's location. If this is the case, the delivery can be made from that stocking point. If the products are stored elsewhere, two supplementary questions arise.

The first condition is the availability of the products at other stocking points. The second condition is the corridor of delivery time if production is possible onsite. If the mean lead time is shorter than the delivery-time corridor and the loading of the work systems is in a normal state, the products are manufactured at the nearest production site.

On the same basis, if production takes longer than the delivery time, the costs for transport have to be set off against the penalty clause or the possible costs if the customer rescinds the order.

If the transport time and transport costs are negligible, logistical criteria can be taken into account for the allocation. Considering the stock of raw material and half-finished products, a due-date oriented and capacity-based scheduling of the work systems has to be carried out. This has to take account of actual work-inprogress. The existence of redundancies in a network allows the simulation of possible manufacturing alternatives.

If the scheduled lead time is insufficient, special measures have to be taken, such as capacity adjustment, or the subcontracting of orders as shown below which, in a way, is a type of order allocation.

\subsubsection{System supported subcontracting}

The overload of work systems requires the balancing of the loading to achieve maximum network performance. This performance has to be rated in relation to logistic objectives like inventory and lead time. An inappropriate loading at single work systems slows down the material flow of the whole process chain. The greatest necessity for a reduction of loading is found in those work systems which have the highest discrepancy between planned incoming work and available ca- 
pacity. For such discrepancy, proposals for solutions can be generated automatically.

The relation of incoming work to capacity is called the degree of demand. This degree can be derived from the planned work and capacity and shows the overload of a system. The degree of demand can be calculated for every work system. It can be sorted from the highest to the lowest degree. This leads to a list of systems in which measures have to be taken to ensure logistical balance. The throughput diagram of the system at the top of the list can be plotted with the progress of the input and output of the same system. The difference between the two shows the trend of the inventory and allows an estimate concerning the range.

Because all the orders are scheduled, a list of them can be derived from the throughput diagram. Orders which are suitable for subcontracting can be marked. By means of a simulation without these orders, the future situation of the work system can be controlled. The amount of correction necessary - either more or fewer orders to contract out - depends on the desired system situation. When the corrections have been made, the list of orders for contracting out can be con-

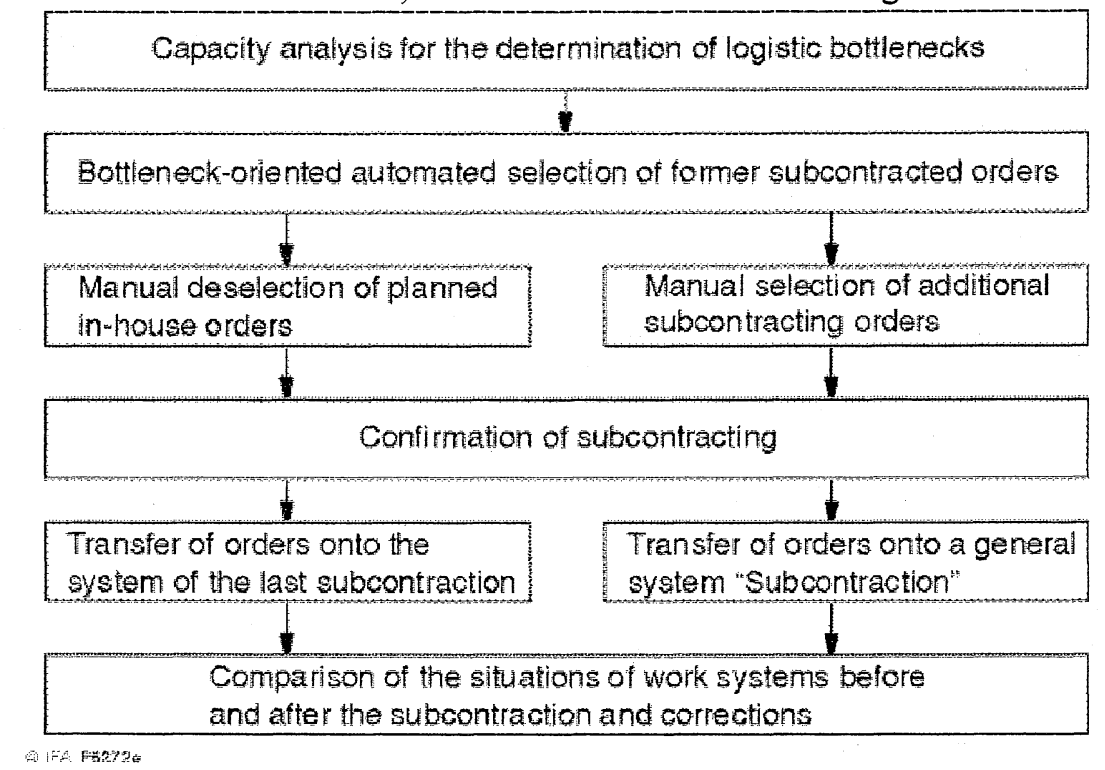

firmed.

Figure 5 Process for system-supported subcontracting

The next step is to check which of the partners' work systems are able to process these orders. The suitable orders have to be scheduled in the same way as at the original manufacturer, and the due dates as well as the loading and the additional transport expenditure have to be rated. The decision whether to manufacture in- or outside has to be made in light of the primary network objectives. In 
the case of a decision for outsourcing, the orders are then converted into subcontracting orders and completed by the respective partners.

\subsubsection{Analysis of logistics potentials}

In addition to the balance of orders between redundant systems, the network coordinator can control other logistics potentials as well. The reduction of the overall inventory is one of the main objectives to reduce the tied up capital as well as the lead time. On the one hand this increases the flexibility of the network, because the response time diminishes; and on the other hand. the variation of the lead time also decreases accordingly.

The reduction of lead time can be managed by load-oriented planning and control and by the use of structural changes. For example, the effect of a variation of lot sizes on the performance and the lead time in work systems can be controlled by plotting logistic operation curves (Wiendahl 1996).

Besides this known method, the development of the methods for a synchronization of manufacturing and storing areas (Wiendahl/Fastabend 1997) as well as the balance of stocks (Wiendahl/Helms 1998) promise the improvement of network efficiency and qualify for use in coordination tasks.

\section{CONCLUSION AND OUTLOOK}

The cooperation of already efficient operating enterprises in networks promises a competitive advantage for the companies. To achieve this coordination is especially important. To allow the coordinator to manage his tasks satisfactory, it is particularly necessary to fulfil structural requirements. The reluctance of enterprises towards logistic instructions is a handicap for the balance of networks. The existence of a logistics coordinator with his tasks and his role have to be accepted by the partners just like the rules for cooperation. The more the concepts of operational networks and virtual enterprises gain importance, the more extensive the function of a coordinator will be and the more acceptance this role will gain.

The problems of coordination in production networks still predominate, but there are already some approaches to solving the logistical conflicts if the objectives are well defined. The growing importance of such roles as coordinators or brokers will produce specialists in this field, just like the manufacturing specialists. The role of logistics will equally become much more important than it is today.

\section{REFERENCES}

Buse, H. P.; Luczak, H.; Pfohl, H.-Chr.; Stengel, R. von; Weber, J. (1997) Wandelbarkeit von Produktionsnetzen, in Vision Logistik - Logistik wandelbarer Produktionsnetze, HNI-Verlagsschriftenreihe, Paderborn 
Wahlers, T.; Mittendorf, M. (1997) Supporting the Design of Logistically Friendly

Products, International Forum on Design for Manufacture and Assembly, Newport, Rhode Island

Wiendahl, H.-P.; Fastabend, H. (1997) Synchronization of logistic processes based on coupling operating curves. $29^{\text {th }}$ CIRP International Seminar on Manufacturing Systems, May 11-13 1997, Osaka University, Japan

Wiendahl, H.-P.; Helms, K. (1998) Variable Production Networks - Successful Acting in an Alliance of the Best, designated for publication in: "Organizing the Extended Enterprise", Chapman\&Hall, London

Wiendahl, H.-P. (1996) Load-oriented Production Control, Springer, Berlin 